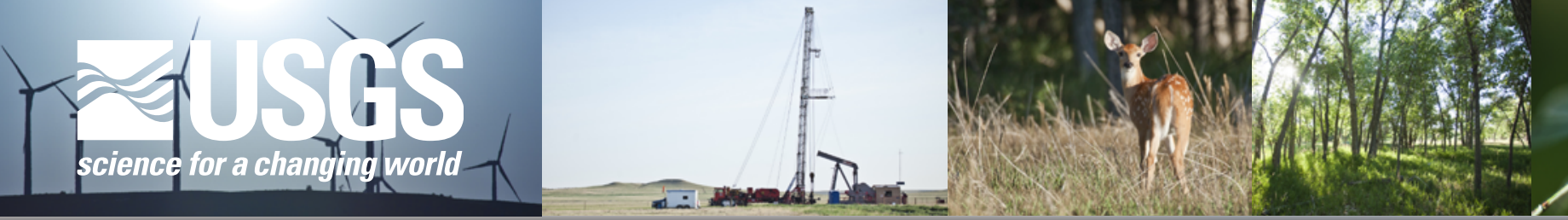

\title{
North Central Climate Science Center-Science Agenda 2012-2017
}

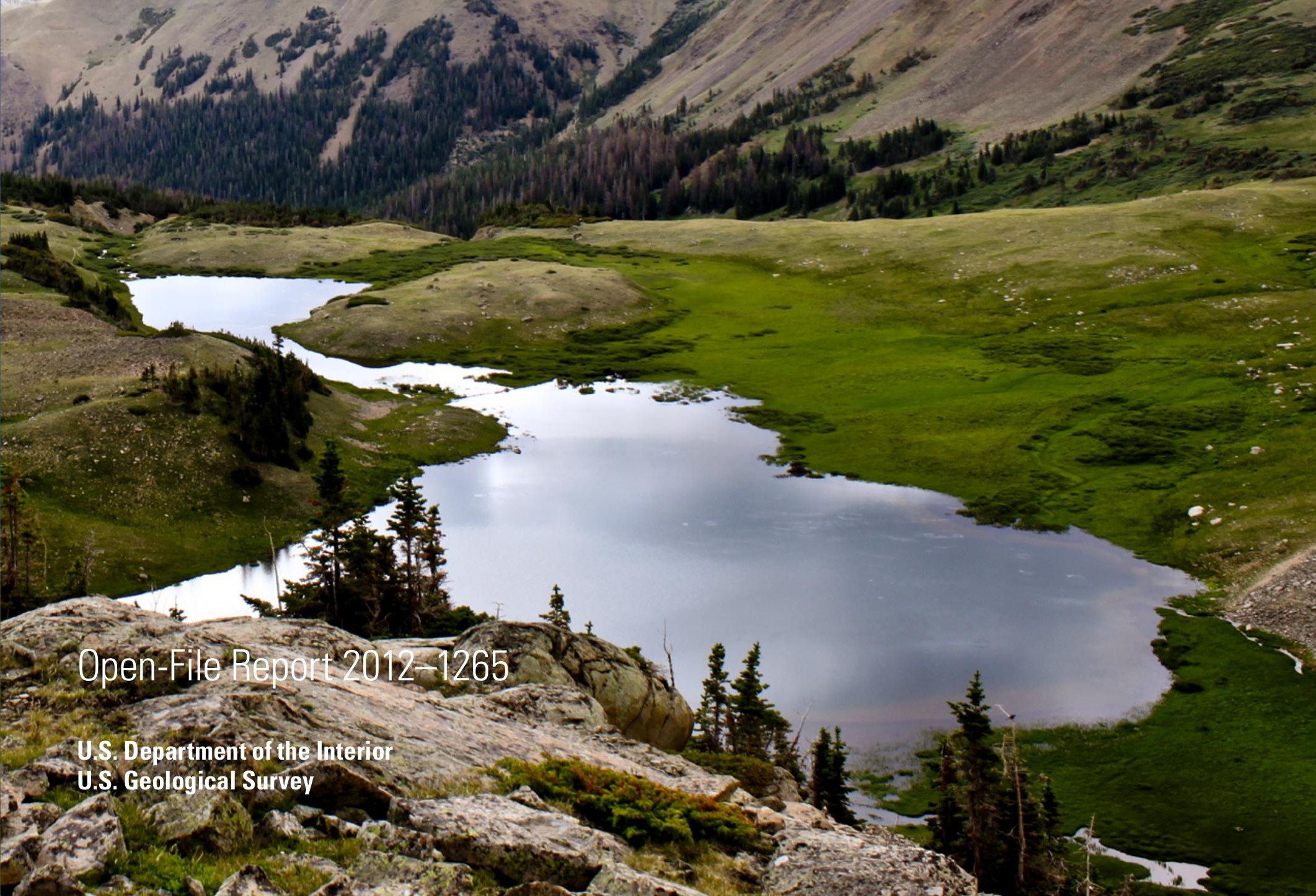




\section{North Central Climate Science Center- Science Agenda 2012-2017}

Edited by Jeffrey T. Morisette

Director, Department of the Interior North Central Climate Science Center

U.S. Geological Survey

Open-File Report 2012-1265 


\title{
U.S. Department of the Interior \\ KEN SALAZAR, Secretary \\ U.S. Geological Survey \\ Marcia K. McNutt, Director
}

\author{
U.S. Geological Survey, Reston, Virginia: 2012
}

For more information on the USGS - the Federal source for science about the Earth, its natural and living resources, natural hazards, and the environment, visit http://www.usgs.gov or call 1-888-ASK-USGS.

For an overview of USGS information products, including maps, imagery, and publications, visit http://www.usgs.gov/pubprod

To order this and other USGS information products, visit http://store.usgs.gov

Any use of trade, firm, or product names is for descriptive purposes only and does not imply endorsement by the U.S. Government.

Although this information product, for the most part, is in the public domain, it also may contain copyrighted materials as noted in the text. Permission to reproduce copyrighted items must be secured from the copyright owner.

Suggested citation:

Morisette, J.T., ed., 2012, North Central Climate Science Center-Science agenda 2012-2017: U.S. Geological Survey Open-File Report 2012-1265, 19 p. 


\section{Contents}

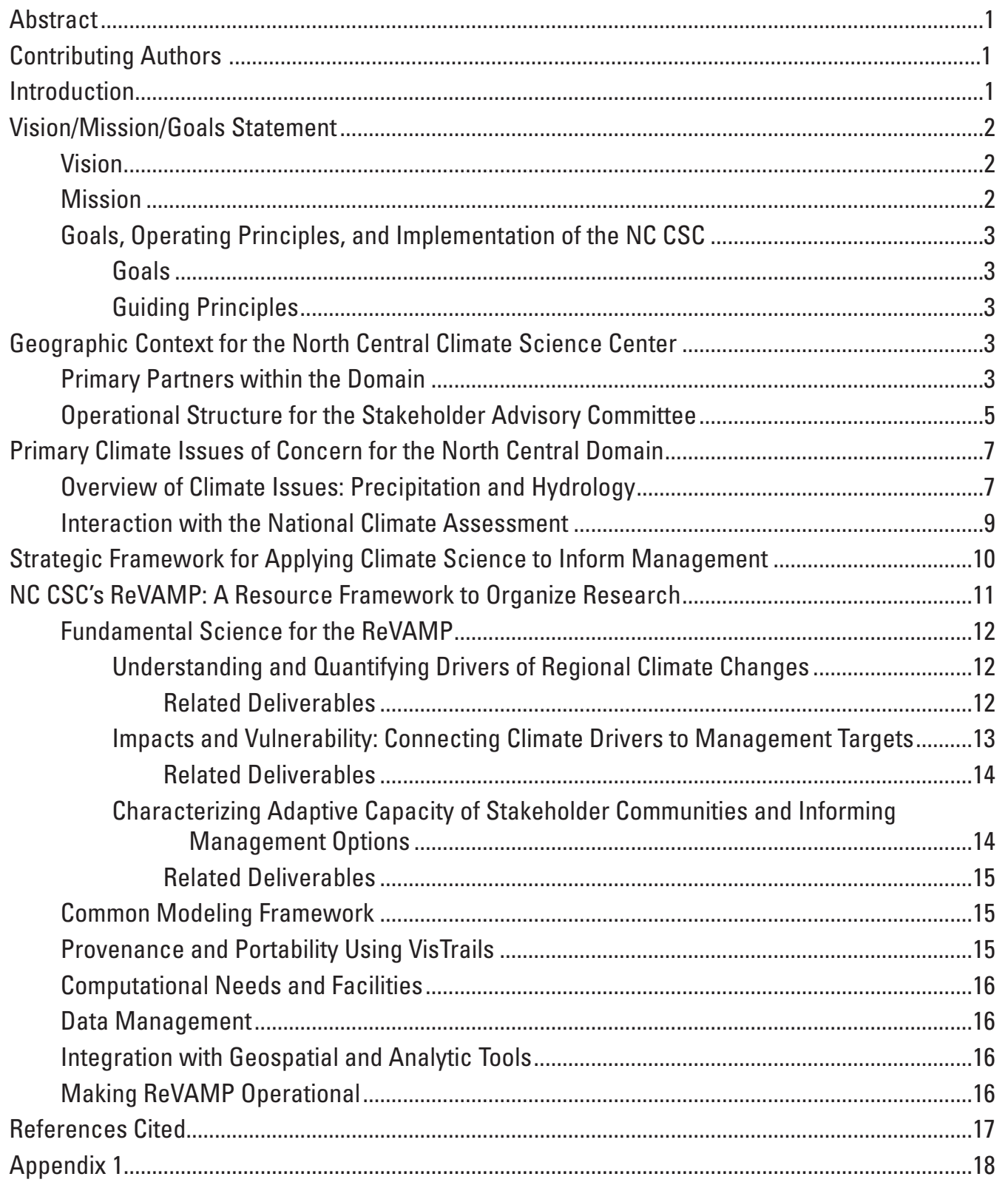

\section{Figures}

1. Time frame and major components of the five-year science agenda for the North Central Climate Science Center

2. Spatial domain of the North Central Climate Science Center, $(A)$ within the context of the other science centers in the contiguous 48 States and the four Landscape Conservation Cooperatives that overlap the North Central Region and $(B)$ interpreted as the ecologically meaningful Missouri River basin.. 
3. Nine members of North Central University Consortium (NCUC) ........................................

4. Missouri River basin streamflow trends 1957-2008....................................................

5. Projected year 2050 temperature (top) and precipitation (bottom) for Steamboat Springs and La Junta, Colorado .................................................................................

6. National climate assessment regions ..........................................................................

7. Framework for developing climate change adaptation strategies .................................11

8. How impact and vulnerability research bridges between climate information and management objectives ..........................................................................................13

\section{Table}

1. Current list of the North Central Climate Science Center's Stakeholder Advisory Committee 


\title{
List of Acronyms
}

\author{
CESM Community Earth System Model \\ CIDA Center for Integrated Data Analytics \\ CLM Common Land Model \\ CSC Climate Science Center \\ CSM Colorado School of Mines \\ CSU Colorado State University \\ CU University of Colorado \\ DOI Department of Interior \\ IPCC Intergovernmental Panel on Climate Change \\ ISU lowa State University \\ KSU Kansas State University \\ LC MAP Landscape Conservation Management and Analysis Portal \\ LCC Landscape Conservation Cooperatives \\ MODIS Moderate Resolution Imaging Spectroradiometer \\ MSU Montana State University \\ NC CSC North Central Climate Science Center \\ NCA National Climate Assessment \\ NCAR National Center for Atmospheric Research \\ NCCWSC USGS National Climate Change and Wildlife Science Center \\ NCPP National Climate Prediction and Projections \\ NCTC National Conservation Training Center \\ NCUC North Central University Consortium \\ NESII NOAA's Environmental Software Infrastructure and Interoperability \\ NOAA National Oceanic and Atmospheric Administration \\ S.0. Secretarial Order \\ UMt University of Montana \\ UNL University of Nebraska-Lincoln \\ USGS U.S. Geological Survey \\ UW University of Wyoming
}




\title{
North Central Climate Science Center-Science Agenda 2012-2017
}

\author{
Edited by Jeffrey T. Morisette \\ Director, Department of the Interior North Central Climate Science Center \\ U.S. Geological Survey
}

\section{Abstract}

The information presented here provides the five-year science agenda for the North Central Climate Science Center. It is meant to be a high-level guide that describes the spatial context of the center, the primary partners and stakeholders, and the strategic framework the center will use in applying climate science to inform management.

\section{Contributing Authors}

This science agenda represents input from a wide range of contributors (see appendix 1). The first contributors were those involved with the initial science agenda developed under the direction of Dr. Jay Hestbeck, U.S. Geological Survey (USGS), while he was serving as the North Central Climate Science Center's (NC CSC) Interim Director in 2011. The second group involved combined input from the NC CSC Stakeholder Advisory Committee (SAC) and USGS centers in the region, with consultation from the NC CSC University Consortium (NCUC) through a two-day strategic planning meeting, April 30 and May 1, 2012, at Montana State University, Bozeman, Montana. The meeting was co-led by the USGS NC CSC Director, Dr. Jeffrey T. Morisette, and University Director, Dr. Dennis Ojima.

\section{Introduction}

The Department of the Interior (DOI), Secretarial Order (S.O.) No. 3289, signed on September 14, 2009, and amended February 22, 2010 (Salazar, 2009), established coordination of the Department's response to climate change impacts on the Nation's resources. The eight regional DOI Climate Science Centers (CSC) established by S.O. 3289 have been implemented by the United States Geological Survey (USGS) National Climate Change and Wildlife Science Center (NCCWSC).
This science agenda provides one of four foundational documents that will be used to guide future work at the center. The additional three documents, the first two of which are in preparation, include the following:

- NCCWSC's “USGS National Climate Change \& Wildlife Science Center Science Agenda" (NCCWSC, written commun. 26 June 2012), which provides a context and framework for the climate change impact research that will be conducted or coordinated by the NCCWSC and its associated regional climate science centers.

- NCCWSC's “Regional Climate Science Center Implementation Document" (NCCWSC, written commun. 26 June 2012), which provides detailed information on the relationship between the regional climate science centers and the DOI, the USGS national programs, the Landscape Conservation Cooperatives (LCC), and other Federal agencies, as well as center staffing, funding, and communication plans.

- NCCWSC's data management policy, ${ }^{1}$ and

- NC CSC's strategic planning meeting (April 30May 1, 2012, at Montana State University, Bozeman, Montana) report, ${ }^{2}$ which provides a benchmark description of both stakeholder needs and partners' capacity.

These documents are represented in the lower portion of figure 1 to represent their foundational nature upon which other efforts will be built. The additional components in figure 1 are described below.

\footnotetext{
${ }^{1}$ https://nccwsc.usgs.gov/content/data-policies-and-guidance.

${ }^{2}$ http://www.doi.gov/csc/northcentral/upload/NC-CSC-science-planningworkshop-report-May-2012.pdf.
} 


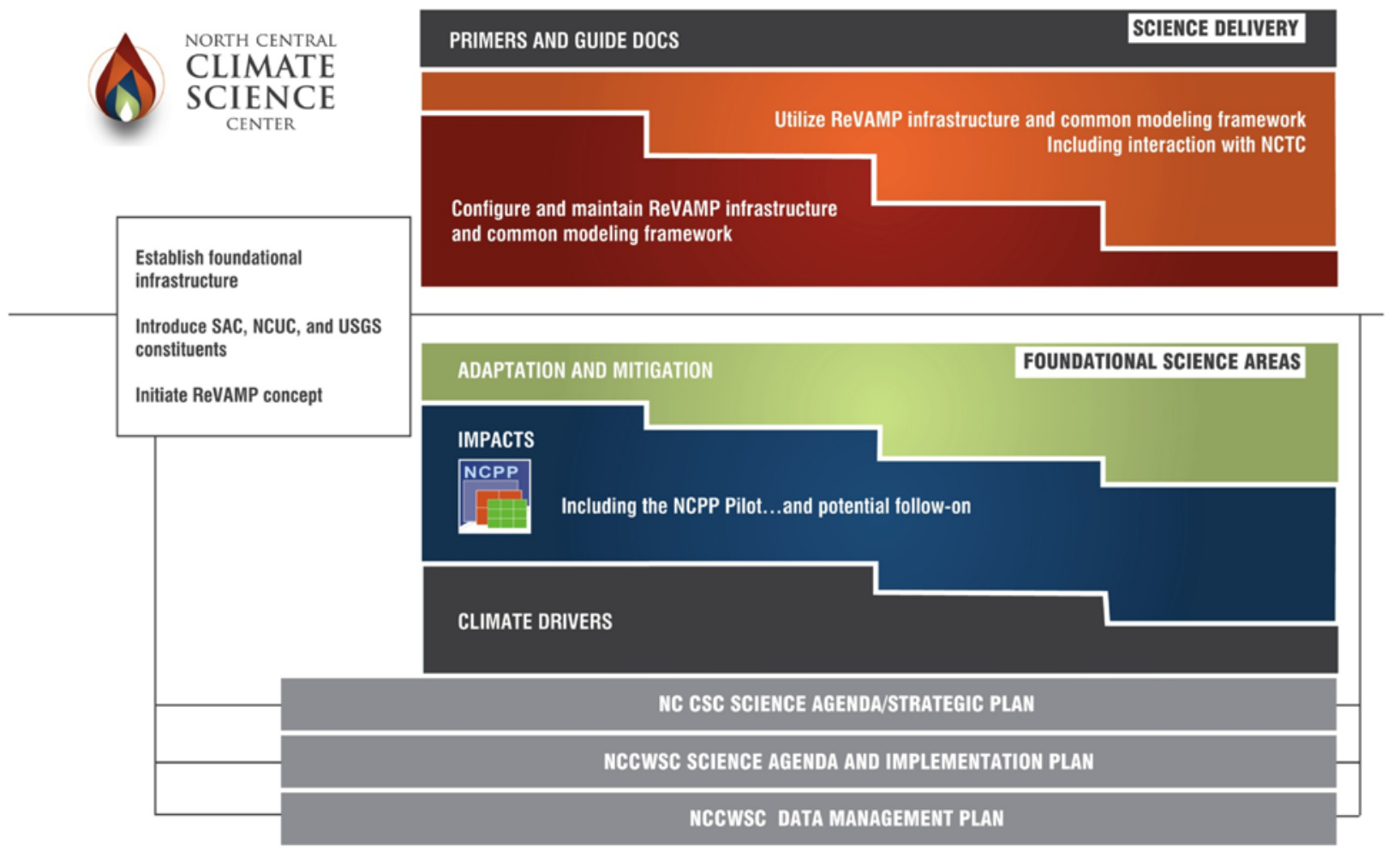

\begin{tabular}{|l|l|l|l|l|}
\hline YEAR 1 & YEAR 2 & YEAR 3 & YEAR 4 & YEAR 5 \\
\hline
\end{tabular}

\section{\STRATEGIC PLANNING MEETING REPORT: BASELINE OF NEEDS AND CAPACITY}

Figure 1. Time frame and major components of the five-year science agenda for the North Central Climate Science Center.

\section{Vision/Mission/Goals Statement}

\section{Vision}

Secretarial Order 3289 states that

“...the United States Geological Survey (USGS) has been developing regional science centers to provide climate change impact data and analysis geared to the needs of fish and wildlife managers as they develop adaptation strategies in response to climate change."

Secretarial Order 3289 continues that the regional climate science centers should

“...broaden their mandate to encompass other climate-change-related impacts on Departmental resources... (to) synthesize and integrate climate change impact data and develop tools that the Department's managers and partners can use when managing the Department's land, water, fish and wildlife, and cultural heritage resources."

The vision of the NC CSC extends the national DOI scientific vision, as expressed in the quote above, to the specific regional needs of the North Central domain. The vision for the NC CSC is a coordinated and integrated regional approach to the management of the Department's land, water, fish and wildlife, and cultural heritage resources in the region that utilizes the best possible understanding of past, present, and future climate into the decision process.

\section{Mission}

The mission of the NC CSC is to provide the best available climate science and tools to inform natural resource management within the North Central Domain. The NC CSC will provide the tools and information needed by managers to understand potential impacts and adaptation strategies for a broad range of natural, cultural, energy, and other resource management activities. This will be done in conjunction with the National Climate Change and Wildlife Science Center and coordinated with the activities of the other regional climate science centers. The three main constituent groups for the center include the North Central University Consortium (NCUC), USGS centers in the region, and the Stakeholder Advisory Committee (SAC). 


\section{Goals, Operating Principles, and Implementation of the NC CSC}

\section{Goals}

The goals attempt to define "what" the center will be doing. The goals are to

- Coordinate and guide the compilation and application of existing climate information, including regional and near-term projections, to inform resource managers, and to improve that information through enhanced regional climate modeling,

- Understand climate impacts and consequences on key regional sectors; natural, cultural, and energy resources; and ecosystem goods and services,

- Evaluate vulnerability of major regional assets and sectors, synthesizing physical, ecological, and social perspectives that include assessment of adaptive capacity and considers human livelihood, health, and safety, and

- Develop and improve decision support tools in collaboration with stakeholders to evaluate (alternate) management and response strategies to address climate change issues.

These four goals will be met through integrated, crossdisciplinary analysis, synthesis of information across scales and sectors throughout the region, and ongoing and effective iterative engagement with managers, decision makers, and the public.

\section{Guiding Principles}

The guiding principles of the NC CSC broadly describe "how" the center will conduct its business. Based on the collective experience of the center staff, the NCUC, USGS centers in the region, the Stakeholder Advisory Committee (SAC), and initial conversations between these groups, the guiding principles are as follows:

Principle \#1: Build on existing documents, assessments, indicators, and frameworks (in other words, don't "reinvent the wheel").

Principle \#2: Understand and demonstrate to resource managers the implication of a climate where means and moments of the temperature and precipitation distribution vary over time (that is, help managers understand the implications of a nonstationary climate).

Principle \#3: Start with the end user in mind and prioritize research that is useful and usable.
Principle \#4: Consider the center as a coordinated research team (and not a funding center), and focus on the unique capabilities of both the team and a coordinated regional initiative.

Principle \#5: Respect the unique demands and constraints on the stakeholders and research partners (which represent a wide array of Federal, State, and university employees where each institution has its own set of constraints and incentives).

\section{Geographic Context for the North Central Climate Science Center}

\section{Primary Partners within the Domain}

The National Climate Science Center boundaries, by design, allow CSCs to cross the boundaries as the science questions dictate (fig. 2A). However, the geographic extent of the NC CSC that is perhaps most ecologically and physically meaningful to our stakeholders and partners is the upper Missouri River basin (fig. 2B). The Missouri River basin can be categorized into four specific ecological units: (1) free-flowing (upstream of the reservoir system), (2) remnant floodplains (between reservoirs), (3) channelized reach (lower one-third of river; that is, "lower river"), and (4) reservoirs (National Academy, 2002). The NC CSC will focus on the domain covered by units 1,2 , and 4 . It is important to note that the NC CSC will consider all land and habitats associated with this geographic area and not just riverine habitats. The upper Missouri River basin is considered the focus area, but work and attention outside that area is acceptable if such is dictated by management targets and studies relevant to the stakeholders.

The organization of the NC CSC and its interaction with its SAC, NCUC, USGS centers, and other Federal, State, and tribal organizations will follow the guidance from the NCCWSC Implementation plan (NCCWSC, written commun, 26 June 2012). The particular entities represented by the NCUC are shown below (fig. 3). The people and entities represented on the NC CSC's SAC are listed in table 1. (The information in table 1 was current at the time of this publication; an upto-date list of NCUC and SAC members as well as the USGS centers within the region are maintained on the NC CSC Web page under "Partners."3) The NC CSC's strategic planning meeting (April 30-May 1, 2012, at Montana State University, Bozeman, Montana) brought these partners together. A description of both stakeholder needs and partners' capacity is contained in the report from that meeting ${ }^{2}$ and reflected in this five-year science plan.

Colorado State University (CSU), the host university (the lead administrative "home"), and eight consortium partners who collectively provide unique and complementary expertise 

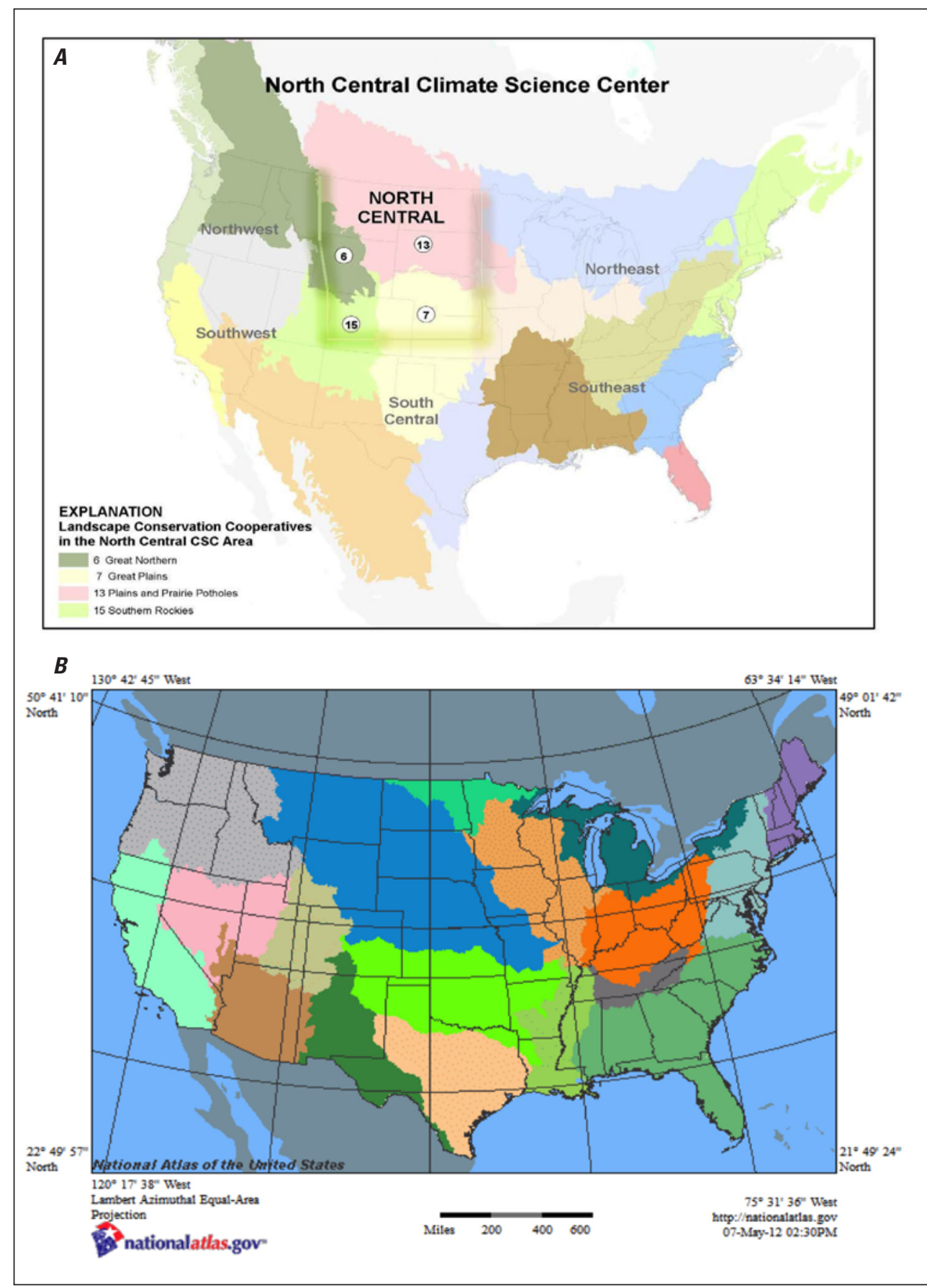

Figure 2. Spatial domain of the North Central Climate Science Center, $(A)$ within the context of the other science centers in the contiguous 48 States and the four Landscape Conservation Cooperatives that overlap the North Central Region and $(B)$ interpreted as the ecologically meaningful Missouri River basin (shown in blue). 


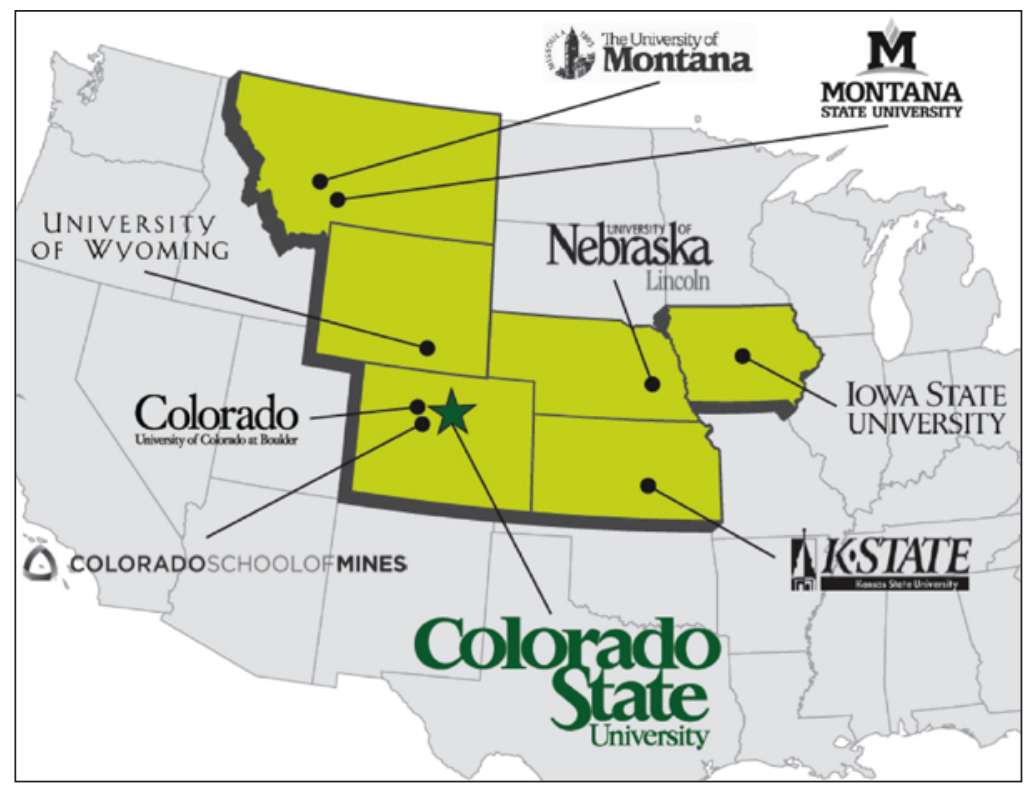

Figure 3. Nine members of North Central University Consortium (NCUC)

to the NC CSC. The other consortium members include University of Colorado (CU), Colorado School of Mines (CSM), University of Nebraska-Lincoln (UNL), University of Wyoming (UW), Montana State University (MSU), University of Montana (UMt), Kansas State University (KSU), and Iowa State University (ISU). Procedures for interaction between the NCUC and the NC CSC will follow the guidance in the NCCWSC Implementation Plan (NCCWSC, in prep. b). The NC CSC will look to have one person serve as the primary representative from each university. This representative is expected to be the liaison between the science needs of the NC CSC and the research and capacity available at their institution. Meetings and (or) conference calls with the NCUC representatives will occur two to four times per year, with face-to-face meetings at least once a year. These face-to-face meetings will include the SAC and provide an opportunity to review annual progress and plan future activities.

\section{Operational Structure for the Stakeholder Advisory Committee}

Executive-level oversight of the NC CSC is provided by a Stakeholder Advisory Committee (SAC) (table 1) that can be composed of individuals from Federal and State agencies and Tribal Nations. The SAC may also contain several nonvoting members from the scientific community to ensure a broader discussion of priority science issues. Initially, these ex officio members will be the University Director (Ojima), the Director of Applications at the National Center for Atmospheric Research (NCAR, Buja), and a representative from the National Climate Change and Wildlife Science Center (O'Malley). The Chairman of the SAC is the USGS Regional Director, or appointed delegate, for the Southwest Region. Meetings and (or) conference calls will occur on an as-needed basis with the annual in-person meetings occurring in conjunction with the NCUC as mentioned above.

This document, the 2012-2017 Science Agenda, was developed in conjunction with the SAC who provided input at the Bozeman meeting ${ }^{2}$ and provided comments on the draft. The following framework and fundamental science topics were vetted with the SAC, and the NC CSC will look to the SAC to actively engage in the framework described below. 
Table 1. Current list of the North Central Climate Science Center's Stakeholder Advisory Committee.

\begin{tabular}{llll}
\hline Affiliation & Last name & First Name \\
\cline { 1 - 2 } USGS Southwest Regional Office & Day & Warren \\
LCC: Plains and Prairie Pothole (FWS-R3) & Nelson & Rick \\
LCC: Great Northern (FWS-R6) & Converse & Yvette \\
LCC: Great Plains (FWS-R2) & Whitlaw & Heather \\
LCC: Southern Rockies (FWS-R6) & Johnson & Kevin \\
LCC Science coord.: Plains and Prairie Pothole & Olson & Mike \\
LCC Science coord.: Great Northern & Finn & Sean \\
LCC Science coord.: Great Plains & Broska & James \\
LCC Science coord.: Southern Rockies & Rice & John \\
Tribal Representative: Flandreau Santee Sioux Tribe & Schumacher & Bill \\
Tribal Representative: Northern Arapaho Tribe & Collins & Gary \\
U.S. Fish and Wildlife Service & Torbit & Steve \\
U.S. National Park Service & Whittington & Tammy \\
U.S. Bureau of Land Management & Kitchell & Katherine \\
U.S. National Oceanic and Atmospheric Administration & Neff & William \\
USDA Forest Service & Hill & Alison \\
U.S. Environmental Protection Agency & Farris & Laura \\
U.S. Bureau of Reclamation & Davis & Gary \\
U.S. Army Corps of Engineers & Thompson & Brad \\
Dept. of Energy, National Renewable Energy Lab & Kutscher & Chuck \\
\hline ex officio or non-members: & & \\
\hline (ex officio) National Center for Atmospheric Research & Buja & Lawrence \\
(ex officio) North Central University Consortium & Ojima & Dennis \\
NCCWSC representative & O’Malley & Robin \\
\hline
\end{tabular}




\section{Primary Climate Issues of Concern for the North Central Domain}

\section{Overview of Climate Issues: Precipitation and Hydrology}

Climate in the NC CSC is strongly connected to topography of the Rocky Mountains and vegetation and soil properties of the Great Plains. Surface hydrology, a key driver of ecological diversity and wildlife abundance, is determined by the interaction of these landforms and weather. For example, about two-thirds of spring and summer rainfall originates from a land source, primarily from within the $\mathrm{NC} \mathrm{CSC} \mathrm{region} \mathrm{but} \mathrm{also} \mathrm{from} \mathrm{land} \mathrm{residing} \mathrm{north,} \mathrm{south,} \mathrm{or}$ southwest of it (Brubaker and others, 2001); whereas, the bulk of mountain snowpack has an oceanic source. The path of weather systems as they move from west to east and their storm track's predominant north-south position determine the pattern of dry and wet subregions within the NC CSC region. Recent changes are evident in variability of streamflow trend across the Missouri River basin. Streamflow has decreased in the West and has increased in the East (see fig. 4), and the pattern indicates change in the terrestrial hydrology budget. This trend influences the landscape limnology in the domain, the citizens, fish, and wildlife that rely on the water from lakes and rivers, as well as the crops or other vegetation that rely on the moisture. A significant issue for the $\mathrm{NC} \mathrm{CSC} \mathrm{to}$ consider is the persistence of this trend as well as the location and variability of the transition zone separating the "dry West" from the "wet East."

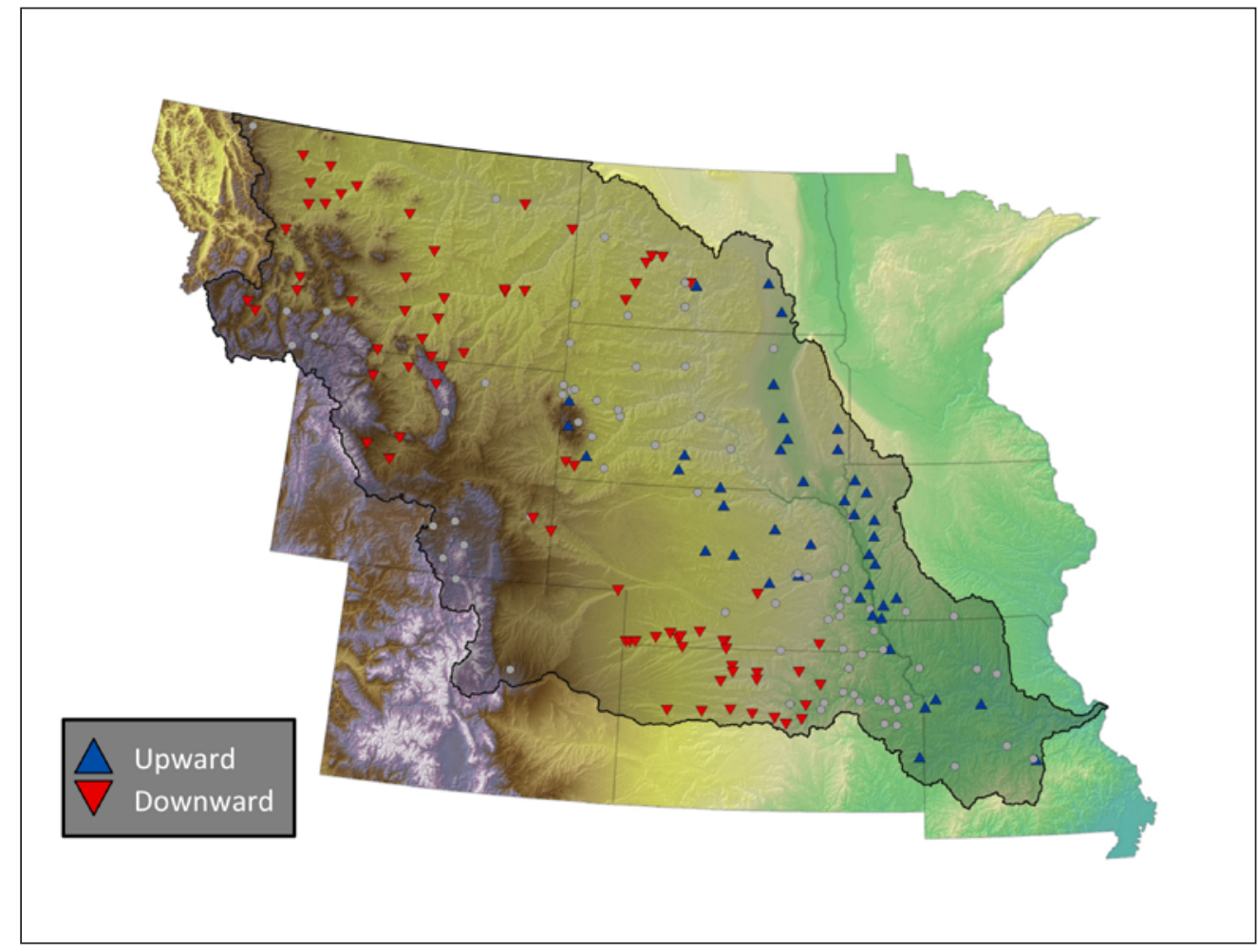

Figure 4. Missouri River basin streamflow trends 1957-2008. Blue triangle indicate an increase, Red/down triangles indicate a decrease, and gray circles represent no statistically significant change $(\delta=0.20)$. 
Also of concern for the NC CSC regional climate analysis is that climate projections for the region are much more confident for temperature than precipitation. In the western water assessment report "Climate Change in Colorado" (Ray and others, 2008), the authors described results from the Intergovernmental Panel on Climate Change (IPCC) showing that there is only weak agreement among climate model projections whether annual mean precipitation will increase or decrease in Colorado and the north-central region by 2050 , although there is an indication of an increase in precipitation in the winter for much of the north-central region and a decrease in precipitation in summer for the western part of the region. Two locations studied in the report demonstrate the consistency in higher temperature projections (fig. 5, top). However, the range of projected future changes in precipitation is large but is still smaller than the year to year and decadal variability in the historic record. No future trend is detectable yet from the precipitation projections, although there are hints of seasonal shifts (fig. 5, bottom; Ray and others, 2008).
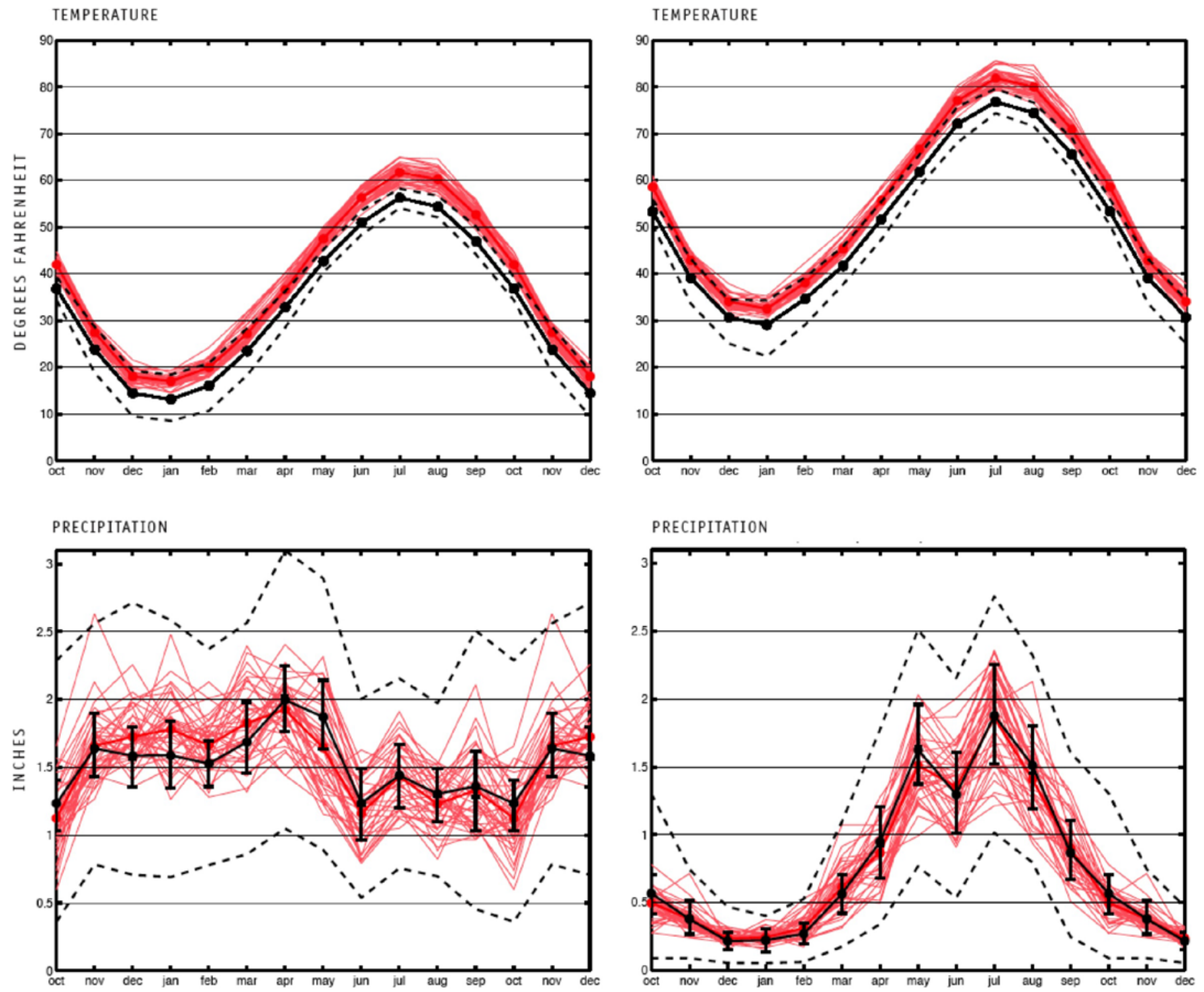

\section{PRECIPITATION}

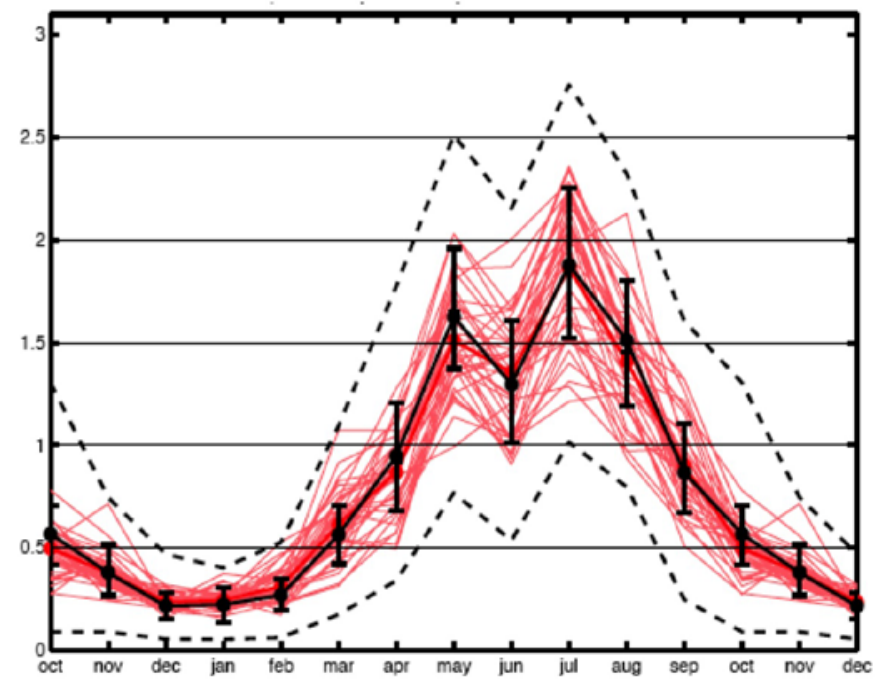

Figure 5. Projected year 2050 temperature (top) and precipitation (bottom) for Steamboat Springs (left) and La Junta (right), Colorado. 


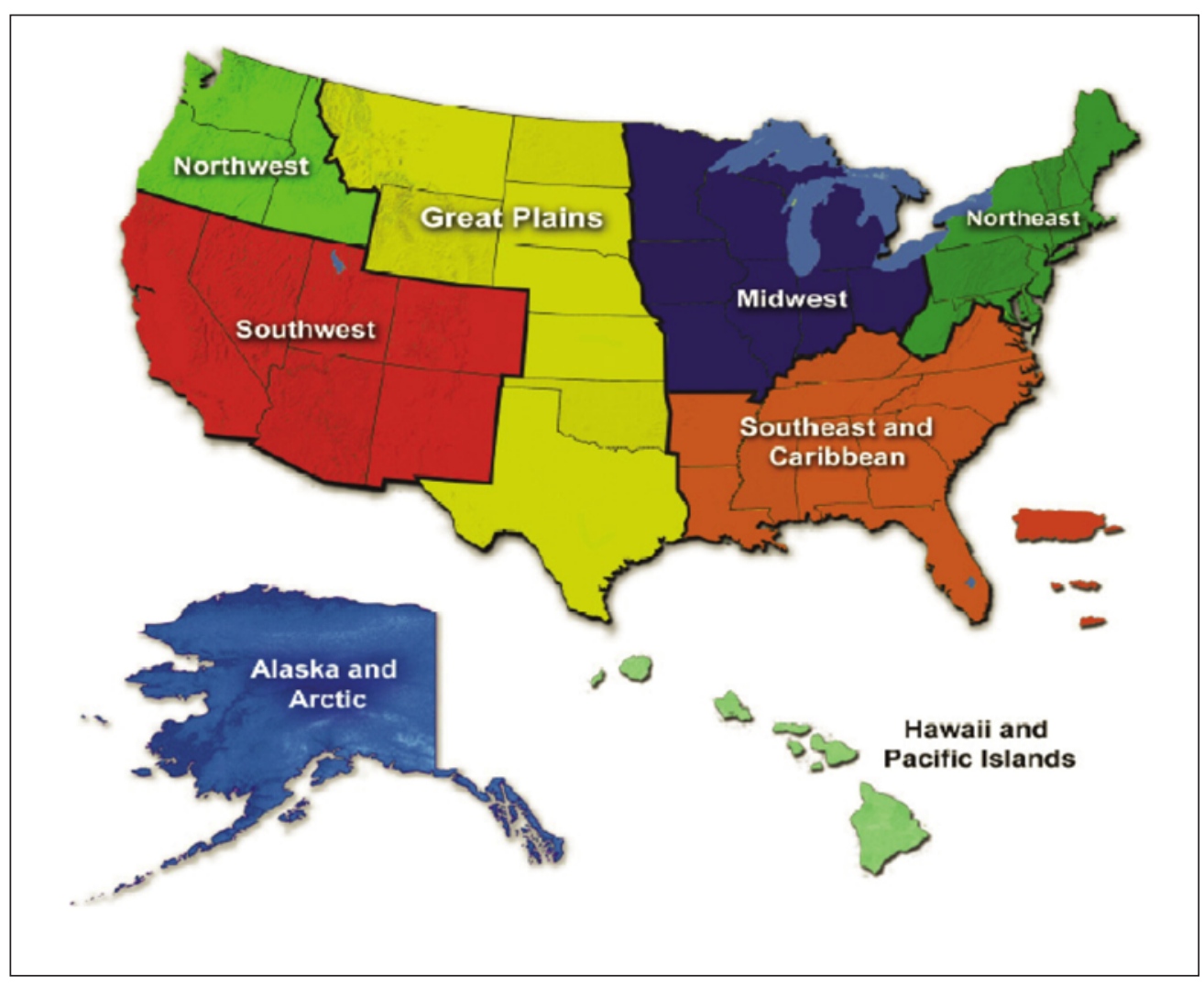

Figure 6. National climate assessment regions.

Water balance drives not only stream flow of the Missouri River and its tributaries (which influences the availability of water for irrigation, municipal use, and navigation) but also impacts the vegetation conditions in the region. Together these factors influence essentially all fish and wildlife populations of concern in the area and thus need to be considered in resource management plans. For this reason, focal point of the NC CSC will be evaluation of the pattern of a drier West and a wetter East in both historical measurements and climate projections. Advancing the understanding of the causes of variability in this pattern and establishing confidence in climate projections of that variability and possible trends will help refine methods to cope with its variability.

\section{Interaction with the National Climate Assessment}

The National Climate Assessment $\left(\mathrm{NCA}^{4}\right)$ is an important and nationally coordinated resource for understanding and communicating climate change science and impacts in the United States. It informs the Nation about already observed changes, the current status of the climate, and anticipated trends for the future. The NCA is comprised of a compilation of eight regional climate assessments (fig. 6) with the NCA Great Plains region overlapping the NC CSC domain. Thus, the NC CSC will use information from the 2013 NCA national report and Great Plains regional report as the base line and primary source of observed changes, the current status, and anticipated trends in climate. Then, as its science agenda is implemented, the NC CSC will look to contribute and coordinate with the 2017 NCA. The NC CSC will also work closely with the National Oceanic and Atmospheric Administration (NOAA) and its program in the region to obtain climate information.

Climate-related challenges across the Great Plains as expressed in the Great Plains Regional Climate Assessment include the following (Ojima and others, in press):

1. Declining water quantity and quality pose the greatest threats from climate change across the Great Plains. Increased competition for water resources will significantly affect both human and ecological communities and systems.

2. Increased intensity and frequency of extreme weather events, as well as changes in rainfall patterns, will create substantial strain on the ecology, economy, infrastructure, and communities of the region. These challenges will affect many economic sectors, including agricultural and energy production and small businesses. 
Although the people of the Great Plains have adapted to past climate challenges, the magnitude of expected changes and impacts will exceed those of previous experience. Proactive adaptation strategies must be developed to address these impacts, and this will require local, regional, and national leadership.

\section{Strategic Framework for Applying Climate Science to Inform Management}

Although there are many guidance documents and publications related to how climate science can help inform management decisions, one of the more relevant, given the mission of the NC CSC and the connection to DOI managers, is "Scanning the Conservation Horizons: A Guide to Climate Change Vulnerability Assessment" (Glick and others, 2011). Climate change vulnerability assessments help identify which species or systems are likely to be strongly affected by projected changes and help us understand why these resources are likely to be vulnerable, including the interaction between climate shifts and existing stressors (Glick and others, 2011).

The framework in the Glick and others (2011) assessment has been adopted for use by the NC CSC for several reasons:

1. The objectives of that framework are closely aligned to those of the NC CSC;

2. The document provides an accessible and logical approach for incorporating climate science into land management through vulnerability assessments;

3. The framework follows international standards for vulnerability assessment (IPCC, 2007);

4. The framework builds on existing and established conservation planning frameworks, such as those of The Nature Conservancy and U.S. Fish and Wildlife Service;

5. The framework can be used to highlight the roles within a vulnerability assessment where the SAC, NCUC, and USGS centers provide the most expertise; and

6. The document is currently the primary text for DOI training on climate change vulnerability assessments.

The first four points are inherent to the Glick and others (2011) document with respect to the mission and goals described above. The fifth and sixth points are expanded on here.

The framework is reproduced here as figure 7 with additional graphics to highlight the NC CSC's understanding of how the CSCs and the SAC can best contribute to that framework. Represented by the green ring on figure 7 , the NC CSC anticipates that its stakeholders provide expertise in steps 1: identifying conservation targets and 4: implementing management options. Represented by the blue ring, the CSCs can leverage ongoing initiatives and research developed through the University Consortium, USGS centers, and other Federal programs to provide resources to assist with steps 2 : vulnerability assessment and 3: identification of management options. The rings intentionally overlap. As indicated by the internal looping circle, each step must be well informed by the preceding step, and implementing the framework for a given target will need to be holistic and iterative across all four steps. Whereas is it helpful to understand that the NC CSC can provide more assistance with steps 2 and 3 , it must be done in close communication and interaction with stakeholders iteratively with steps 1 and 4 of the framework.

The National Conservation Training Center (NCTC) offers a class through the DOI on "Climate Change Vulnerability Assessments," which uses as its primary text the Glick and others (2011) document. The course is designed to guide conservation and resource management practitioners in two essential elements in the design of climate adaptation plans. Specifically, it provides (1) guidance in identifying which species or systems are likely to be most strongly affected by projected climate change and (2) understanding of why these resources are likely to be vulnerable, including the interaction between climate shifts and existing stressors. To date, over 300 people involved with resource management have attended the course (Donna Brewer, NCTC, oral commun., 26 Oct. 2012). So, in the coming years, we anticipate a cohort of DOI and other land managers who will be familiar with the Glick and others (2011) document and its associated framework. We have built the five-year research agenda for the NC CSC to help provide scientific support to this cohort and other resource managers concerned with impacts of climate change.

It is worth mentioning a revised framework recently reported by Cross and others (2012), which presents a similar framework, but with six steps that provide additional detail on climate information and more explicitly accounting for iterating through the process. Though recognizing the utility and need to consider the ideas in Cross and others (2012), because of its eloquence and current use within the DOI, NC CSC will utilize the four-step Glick and others (2011) framework.

One final note on the Glick and others (2011) framework: the NC CSC considers the term "conservation" goals and targets fairly broadly and is taken to include renewable energy and cultural resources. Also, the term "vulnerability assessment" tends to focus on potential negative consequences. The NC CSC is open to consideration of potential positive opportunities that may be presented by future climate changes. Swapping "Assess vulnerability to climate change" with "Assess opportunities from climate change" in step 2 allows for the framework to be applied in such cases.

\footnotetext{
${ }^{5}$ http://training.fws.gov, coarse code $=$ ALC3184
} 


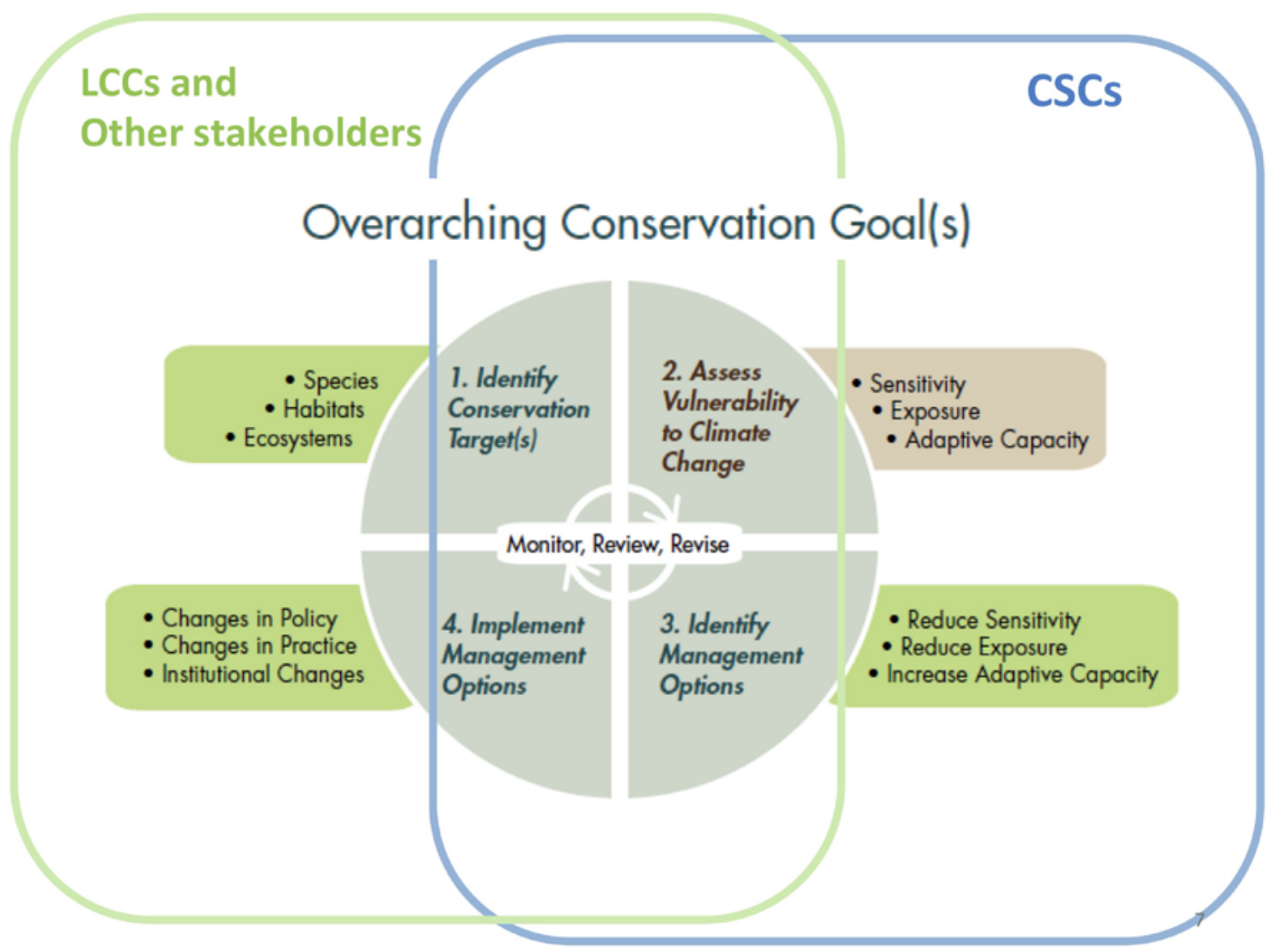

Figure 7. Framework for developing climate change adaptation strategies (taken from Glick and others, 2011) with the additional demarcation showing the NC CSC interpretation of SAC's and CSC's relationship to that framework.

\section{NC CSC's ReVAMP: A Resource Framework to Organize Research}

The "Scanning the Conservation Horizons" document provides a solid framework for the NC CSC as enumerated above. However some of the technical components involved with implementing the framework (including downscaling climate projections, ecological response models, and assessing and understanding uncertainty) are nontrivial. We believe that a typical resource manager or management team attempting to apply this framework (by taking the NCTC course, reading Glick and others (2011) document, or referencing similar framework documents) could use assistance in approaching the fairly complex and varied analysis required. With this, the NC CSC is directing its five-year science agenda toward science delivery through a Resource for Vulnerability Assessment, Adaptation and Mitigation Planning (ReVAMP).
Stakeholders have expressed a desire to have a resource that can help interpret and untangle the ever increasing array of climate information. One suggestion was to consider it the North Central Climate Service Center. Another suggestion was to consider the CSC as a climate information extension program. Stakeholders have asked the NC CSC to focus on management relevance and ensure that land and water managers have access to products AND can use them. Although peerreviewed publications are important, managers have to be able to find and use information/tools (sometimes more quickly than waiting for journal publication). These and other comments, as well as observations from attending the NCTC courses, have established a need for technical assistance in applying climate science to the management process, including vulnerability assessments, adaptation, and mitigation. The ReVAMP concept will help address this need. The five-year plan for the ReVAMP framework is shown in figure 1 where initial focus will be on configuring and maintaining the ReVAMP infrastructure. This activity will start to ramp down while the use of the ReVAMP infrastructure and tools starts to ramp up. 


\section{Fundamental Science for the ReVAMP}

The ReVAMP concept will serve as a centralizing theme to coordinate research done through the NC CSC and will also provide the mechanism by which the NC CSC can help serve stakeholder needs. ReVAMP will include the following three focal areas (which follow closely the components of capacity needed for conservation in light of a nonstationary climate in Jackson and others (2009) and are directly related to the NC CSC goals listed above):

- Understanding and quantifying drivers of regional climate changes,

- Assessing impacts of climate change on the natural resources of the region and the resulting vulnerability of social-ecological system components, and

- Characterizing adaptive capacity of communities and natural resources.

These three research areas and their rough allocation of resources and attention are shown as the "Foundational Science Areas" in figure 1 and described in detail below.

\section{Understanding and Quantifying Drivers of Regional Climate Changes}

Understanding climate drivers is a central theme for all CSCs. Informing the north-central management community on the latest science related to climate drivers in the region and communicating the potential effects is a fundamental and critical element of the NC CSC ReVAMP. Specifically, this research area addresses the "Exposure" bullet in step 2 of the Glick and others (2011) framework (fig. 7).

The climate in the north-central domain is driven by large-scale patterns in atmospheric circulation, the region's complex topography, and effects due to the nature of the local land cover. The multiscale nature of these climate drivers creates patterns of mean climate, climate variability, and climate change that are characterized by dramatic gradients in seasonal and annual temperature, effective moisture, and wind. The resulting climatic variability determines the diversity and distribution of habitats that support species and ecosystems and impacts the potential renewable energy resources for the area. It is necessary, therefore, to use region-specific approaches for developing targeted climatological information that respects the full range of temporal and spatial scales of climate processes in order to understand vulnerability of conservation targets to changing climate.

Regional climate research in the north-central region, spanning the Holocene to the future, is underway by scientists in the USGS, consortium universities, and other Federal researchers. Research connected to the NC CSC within this theme should consider using paleoclimate and historical studies based on pollen, diatoms, tree-rings, geochemistry, lithology, charcoal, streamflow, and historical records to reconstruct past conditions. Climate modeling efforts should focus on both statistically and dynamically downscaled simulations of ecosystem-important climate parameters and evaluation of the scales at which climate model processes are operating within the NC CSC domain.

Climate-driver research for the NC CSC will be directed toward clarifying and quantifying the trajectory of change in past, present, and future climate drivers within the NC CSC domain. Based on the climate issues relevant to the NC CSC domain, the priority considerations for this research area include, but are not limited to, trends and forecasts of precipitation and resulting hydrology and water balance across the west to east moisture gradient. An important part of this research area will be to quantify the nonstationary nature of climate drivers (Milly and others, 2008) for the region and to consider ways to either reduce or deal with the uncertainty of precipitation projections.

\section{Related Deliverables}

This research focus will provide climate information across the region that will be tailored to resource management decision-makers' needs, as well as to inform researchers on the driver of impacts across an array of natural and cultural resource areas, from species, landscapes, biotic and biophysical resources, and ecosystems. This information will be analyzed over historical periods as well as include projections of different scenarios of climate dynamics into the future.

The research activities will analyze available climate datasets for the region to develop a suite of annual, seasonal, and diagnostic indicators of climate features that have potential impact on natural resource management issues across the region. For instance, multidecadal analysis of extreme events related to droughts, floods, and temperature highs and lows will be conducted to characterize changes in climate trends over historic and projected climate datasets. More detailed analysis of growing-degree days, extremes in hot and cold days, precipitation events, snowfall, and seasonal precipitation will be analyzed as related to critical resource management needs.

Development of additional analyses will be done in consultation with SAC. The priorities for this research area and delivery of results will be guided by the plans for adaptation and mitigation goals defined by the agencies, State, local, and Tribal governments represented by the SAC.

Specific deliverables include the following:

- Publications and expert opinion focused on geographic areas and ecosystems/habitats of concern to the Stakeholder Advisory Committee and other clients on our current understanding of climate and climate variability in the region,

- World-class research on regional climate models in the NC CSC domain, with an understanding of how that research fits client-based and management decision activities

- Contributions to the future National Climate Assessment, and 
- Climate information and products that are accessible and useable within the ReVAMP as input to the vulnerability assessment management options components of the framework.

This research area will require more attention in the early years as it represents fundamental science that needs to be established so as to provide input to impacts and adaptation research areas (described below). As such, it will receive more focus and resources in the early years with a slight ramping down in the final years (fig. 1).

\section{Impacts and Vulnerability: Connecting Climate Drivers to Management Targets}

Whereas climate drivers are a fundamental research component for the CSCs, for most management issues climate is often not the primary concern. For example, land managers are more concerned about animal populations or ecosystem services than they are about changes or trends in annual average temperature or precipitation. Yet climate drivers are linked to the conservation targets of concern. This research element is directed toward understanding and quantifying that linkage through ecological response models. Ecological response models, as enumerated in Glick and others (2011), help bridge between climate information and management goals (fig. 8). This research area will utilize information from the climate research area to best accomplish step 2 of the Glick and others (2011) framework (fig. 7).

The NC CSC will be using this research area to explore how climate data can better provide information to managers by way of ecological response models. For this area, the NC
CSC will provide the data-model-management connections (that is, serving as a liaison between all three components). Components of the climate-drivers research area (described above) as well as collaboration with NOAA's National Climate Projections and Predictions (NCPP) program, and other Federal climate-related programs, will work to develop capacities to provide enhanced climate information at relevant spatial and temporal scales, both for historical climate and projections of future climate (the left-most box in fig. 8). The connection with the NOAA NCPP is being explored through a current pilot project that will run through 2013. This pilot will be used to inform subsequent collaboration with NOAA and the NCPP program. ${ }^{6}$

This research area will look to leverage ongoing and active research and expertise in ecological response models where translational climate analysis can advance that work. It is important for the ecological response modeling to also respect the nonstationary nature of climate drivers (Milly and others, 2008) and consider nonstationary drivers when constructing climate derivatives as input into the ecological response models.

The connection to management actions (the right-most box in fig. 8) links this research area to the adaptation and decision-making research areas listed below. The NC CSC is looking to build ecological response modeling that can both (a) be improved with enhanced climate information that respects nonstationarity and (b) serve management issues that have been prioritized by the stakeholders. The ReVAMP infrastructure will facilitate the connections and interactions represented by the two-way arrows in figure 8 (and it is important

\footnotetext{
${ }^{6}$ http://www.doi.gov/csc/northcentral/NCPP-Pilot-Project.cfm
}

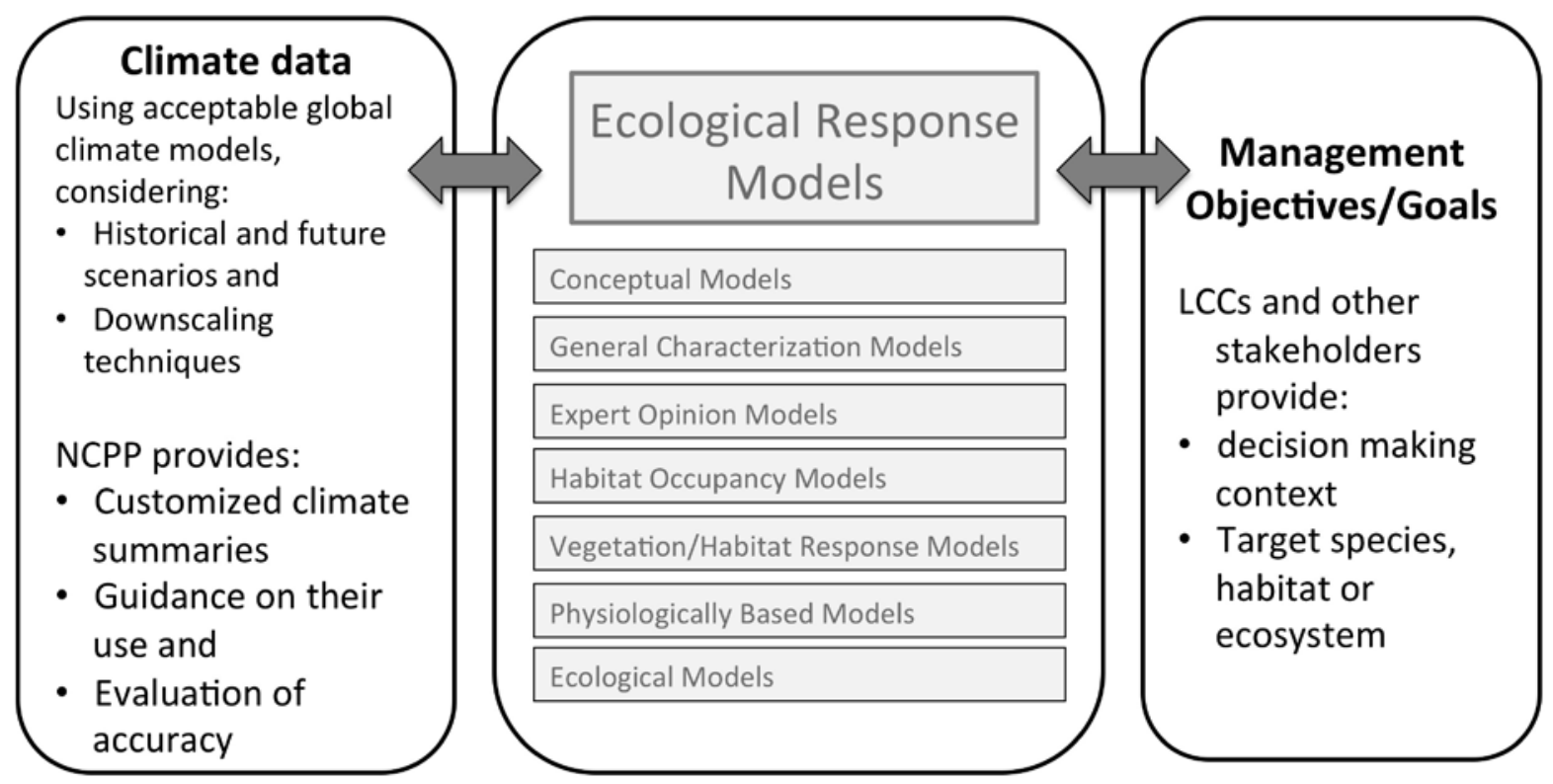

Figure 8. How impact and vulnerability research bridges between climate information and management objectives. 
to note that they are indeed two-way arrows). The NC CSC will facilitate translational information and science/management exchange represented by these arrows. The related research in this focus area must be open to and agile enough to iterate with both the climate-drivers research component and relevant resource management goals and objectives.

\section{Related Deliverables}

The impacts research area will incorporate vulnerability to different exposure and sensitivity of system components to climate effects and drivers to address the nature of the vulnerability. It will build on current observations available in the region and utilize an ensemble of models to enhance the understanding of vulnerability to natural and cultural resources in the region. The vulnerability framework provides an analytical process to identify exposures and sensitivities of a system together, as well as separate parts of the system. Analysis of vulnerability will incorporate regional and temporal aspects to inform managers and researchers about interactions between factors and temporal dimensions of these interactions.

Specific deliverables include the following:

- The ecological-response-modeling component of the ReVAMP, which will link state-of-the-science understanding of climate with resource management decision support tools,

- Habitat integrity factors that influence the productivity and extent of these habitats across various changing environmental conditions,

- Species-level sensitivity of physiological or population limits that would affect the success of the species, and

- Ecosystem service changes that would alter management considerations of these resources.

This research area is seen as essential to make climate data available and relevant to land managers. Early work in this area will be required to demonstrate the utility of the center, and continued work will be needed to take advantage of the improved climate information coming from the climate drivers research (area 1, described above). As such, it will maintain a substantial and sustained focus throughout the life of this five-year plan (fig. 1).

\section{Characterizing Adaptive Capacity of Stakeholder Communities and Informing Management Options}

Connecting to decision makers is one of the main operating principles for the center and integral to its mission. This connection is not always obvious or automatic; it requires not only a strong research program but also a healthy infrastructure for transition, a strong interface with the user community, and continuous evaluation of the process (National Academy, 2000). This research area will ensure the NC CSC has these key components in place.
Adaptive capacity issues come into play in both the 2nd and 3rd steps of the Glick and others (2011) framework (fig. 5). Understanding and evaluation of the adaptive capacity of the social-ecological systems in the north-central region should be an integral component in the development of management strategies to deal with climate change. The vulnerability of natural resources and the adaptive capacity of the social-ecological system vary across the region due to local, State, Tribal, and regional accessibility to social-ecological capital resource assets. The science done through the NC CSC should work toward understanding the availability and use of capital resource assets in the region and how they are, or can be, used for implementing adaptive management practices. This understanding is critical in the development of useful and feasible management strategies.

Recent observations of droughts, fires, pest outbreaks, and habitat loss to wildlife provide examples of potential climate impacts on natural resources (CCSP 2008; Karl and others, 2009), while droughts and fires provide examples of potential climate impacts on social-economic systems and resources ${ }^{7}$. Research under this theme will explore how these climate change features affect local-scale social-ecological systems, trigger threshold events, and create nonlinear interactions across an interwoven set of stressors on resources (CCSP, 2009; Allen and others, 2010), and how these get reflected in local management decisions and practices. A major goal for this theme is to develop a robust decision making approach that acknowledges the sources of uncertainty, incorporates what is known of the system's vulnerabilities, and assesses assets critical to the management entity.

Providing expertise on management options is relevant to the 1st and 4th steps of the framework (fig. 5). As stated above, the primary capability for the 1 st and 4 th elements of the framework will come from the stakeholders. However, the NC CSC will work with its SAC to help identify management targets that are most vulnerable to climate change and iterate and coordinate with entities represented on the SAC as they implement management options. The NC CSC will look for research in this area to develop the criteria for selecting targets and applying the four-step process to those targets. Based on input to-date, the mission of the center, and the operating principles, the criteria for target selection should include an emphasis on regional issues, a clear connection to climate drivers, and an explicit relevance to management decisions.

To identify conservation targets and implement management options, it is imperative to understand the socialeconomic context and drivers. The NC CSC is very committed to identifying end users' needs and understanding and facilitating the incorporation of climate science into management decisions through quantitative decision support tools. As such, research will be directed in this area and the NC CSC will look to coordinate with the USGS Science and Decision Center ${ }^{8}$ as well as the staff and resources available through the NCTC

\footnotetext{
${ }^{7}$ http://www.ncdc.noaa.gov/billions/events

${ }^{8} \mathrm{http}: / / w w w . u s g s . g o v / s d c /$
} 
structured decision-science curriculum 9 . Key components of this research area will include quantitative scenario planning (Kass and others, 2011) and management-decision-based simulation studies (for example, Frid and Wilmshurst, 2009).

\section{Related Deliverables}

This focus area will provide a critical analysis of how the different management entities represented on the SAC and across the region have an ability to implement adaptation and mitigation strategies. This analysis will evaluate the options available to these entities to both address the impacts on the system and identify potential vulnerabilities. This information will provide a framework to build capacity to cope or respond to different stressors. The analysis of capital assets will be made within the decision-making context of these entities and with the help of quantitative decision support tools.

Specific deliverables include the following:

- Detailed information on management options and institutional resources and how these are utilized under various decision-making situations,

- Integration of the information derived from the other research activities above, shared with stakeholders across the region to enhance adaptive capacity, and

- Quantitative decision-support tools for the ReVAMP.

This research area is less developed than the other two focus areas. The first few years will be used to establish a community around these topics, with increasing work and attention as more tools and capacity are established and as the climate data and impact research areas start to yield results (fig. 1). Initial work will lay the foundation for the important work that will happen in later years. The "ramp" for this research area in figure 1 recognizes that this area is still in the developmental stage and resources for the area are expected to increase during the life of this plan.

\section{Common Modeling Framework}

The NC CSC is committed to an open access and shared community platform for the climate analysis, impact assessments, and decision support tools that will result from the research areas listed above. A community-based approach will provide an open platform for co-development of data and analytical sharing and translation of information dealing with climate variables, impacts of climate change, and options related to management plans and adaptation strategies to offset specific vulnerabilities.

The information technology infrastructure developed through NC CSC will adhere to the following principles:

- Most modeling will be done with close collaboration between the decision makers, the climate modeling community, and researchers familiar with

\footnotetext{
${ }^{9}$ http://training.fws.gov/EC/Resources/Decision_Analysis/SDM.htm
}

the relevant ecological, energy, cultural, or management disciplines,

- The modeling tools will be as transparent as possible (avoid "black box" type solutions),

- Software will be configured to take advantage of highperformance computing as it becomes available, and

- The modeling framework will facilitate community input.

Such community-based earth-system development and application studies have been successfully utilized at the National Center for Atmospheric Research (NCAR). The Community Earth System Model $\left(\mathrm{CESM}^{10}\right)$ and submodules, such as the Common Land Model (CLM), have been designed with input from the research and user communities. In this manner the development of the CESM and CLM components proceed in a rapid manner with input of findings from recent research on specific portions of the model and are quickly evaluated for inclusion in the application activities such as the Intergovernmental Panel on Climate Change (IPCC) assessments. The NC CSC will look to follow these successful examples in building a common modeling framework for the region.

It is worth noting that this modeling framework is focused more on analysis and computation than on data input or archives. The NC CSC will work to utilize other national data-related efforts (see Data Management section below).

\section{Provenance and Portability Using VisTrails}

Recently developed scientific workflow and visualization tools will be used to build a common modeling framework. VisTrails ${ }^{11}$ is open source software that can help researchers and managers visualize workflows and display analysis results while capturing the provenance of each model run, including input data and modeling parameters. VisTrails provides a documented, repeatable audit trail of the analysis. follows:

Key advantages to using scientific workflows are as

- It allows for the formalization and tractable recording of the entire analysis process,

- By constructing the model configuration in a way that is fully explicit and tractable, it can allow for easier collaboration by enabling one group to understand what the other has done and to iterate on adjustments or changes,

- By wrapping many disparate tools and custom processing steps in a user-friendly interface, the file management and compatibility burden on researchers is greatly reduced, and

\footnotetext{
${ }^{10} \mathrm{http}: / /$ www.cesm.ucar.edu/

${ }^{11}$ http://www.vistrails.org
} 
- By formalizing the components in a modular setting, VisTrails can incorporate future and additional modeling routines and tools (Morisette and others, in press).

NC CSC research efforts will be directed to evaluate how VisTrails can be used to establish protocols for implementing a common framework for climate modeling, impact assessment, and decision support tools. By integrating modeling workflows in VisTrails, the NC CSC will start to design a system where the outputs from one modeling effort can easily become inputs to subsequent analysis. The built-in documentation capabilities of VisTrails provide a means to ensure transparency, repeatability, and transferability. Use of VisTrails as a common modeling framework will start in year one and ramp up through the entire five years. Ramping up will include adding new ecological response models, incorporating more informed climate information, and expanding the list of conservation targets. The NC CSC has a NASAsponsored project (through 2015) wherein the lead VisTrails developers at Polytechnic Institute of New York University (NYU-Poly) are available to consult on the use and development of VisTrails. Development, evolution, and evaluation of this modeling framework will be done collaboratively between NC CSC and the VisTrails developers with input from the NCUC, USGS and other Federal research centers, and the SAC.

\section{Computational Needs and Facilities}

Given the NC CSC mission - provide the best available climate science and tools to inform natural resource management within the North Central Domain - the center will continually work with large amounts of climate-model data and derived products. The NC CSC will require unfettered access to large computational facilities and resources for day-today operations, ongoing analyses, and long-term projects. Significant amounts of data and derived information will be ingested, processed, and transferred between researchers and managers on a routine basis.

Operationally, NC CSC will work with tens of thousands of individual files. They fall roughly into four categories: computer programs, input data, intermediate data, and output data. Input data, primarily historical and projected climate data, can be tens to hundreds of terabytes; intermediate data files are up to tens of terabytes in size; and output products are on the order of one or two terabytes.

The NC CSC will help coordinate research among the nine universities in its consortium and over 20 USGS research offices, as well as other Federal, State, and NGO collaborators. The center will transfer large amounts of data (on the order of terabytes) regularly between and among the various partners in order to facilitate the variety of processing needs. Large-scale computing will occur at several sites with high-performance computing, which requires moving either input or output datasets. The primary computation resource to be explored for use by the NC SCS is the joint NCAR/UW "Yellowstone" supercomputer. ${ }^{12}$

\section{Data Management}

The NCCWSC has written a policy regarding the sharing of data by collaborators funded partially or entirely by the NCCWSC and (or) the CSCs. ${ }^{1}$ The objective of the policy is to ensure and facilitate full and open access to scientific data and data products. This policy is a binding condition for all NCCWSC and CSC supported projects and the NC CSC will ensure all science conducted through the center will follow the national policy.

In regards to climate data access and modeled output delivery, the NC CSC is specifically looking to leverage off the USGS GeoDataPortal developed at USGS Center for Integrated Data Analytics (CIDA ${ }^{13}$ ) and partner with NOAA's Environmental Software Infrastructure and Interoperability $\left(\mathrm{NESII}^{14}\right)$ Group. The NC CSC will also look to integrate with the Landscape Conservation Management and Analysis Portal (LC MAP ${ }^{15}$ ) and the Global Change Master Directory $\left(\mathrm{GCMD}^{16}\right)$.

\section{Integration with Geospatial and Analytic Tools}

Given the size of climate data, the computing power needed to process it, and its dynamic nature, the NC CSC will explore options for delivering the required data preprocessed, distilled to the relevant information for a given analysis or management need, and delivered on-demand. Ongoing work at the NC CSC is exploring the use of machine-to-machine services to automatically query remote data sets. For example, a current test project is using ESRI image service and associated ArcMap toolbox to allow users to see and analyze remote sensing and climate data products within ESRI applications. This image service can be used in ArcMap as if the data were stored locally, but only the portion of the data covering a specified area of interest is downloaded. From an end user's perspective, the process is seamless and straightforward. Additional mechanisms for delivering these critical but cumbersome data in other applications, such as R, Python, and VisTrails, will be developed in coordination with outside partners.

\section{Making ReVAMP Operational}

ReVAMP will be a community resource for information exchange and analysis in support of resource management

\footnotetext{
${ }^{12}$ http://nwsc.ucar.edu/

${ }^{13}$ http://cida.usgs.gov/

${ }^{14}$ http://www.esrl.noaa.gov/nesii/

${ }^{15}$ https://my.usgs.gov/catalog/?community $=L C+M A P$

${ }^{16} \mathrm{http}: / / g c m d . n a s a . g o v /$
} 
decision making under a nonstationary climate. As a community resource, the NC CSC staff will centrally manage its implementation and support. However, the facility will be governed by the larger partner community consisting of the SAC, NCUC, Federal agencies, and other partners from State and Tribal governments.

We will start with and host a ReVAMP central node at CSU's Natural Resource Ecology Laboratory in conjunction with the nearby USGS Fort Collins Science Center's Resource for Advanced Modeling ${ }^{17}$. The central node will link to other major computational facilities, research results, and communication and outreach activities in the region. The SAC and NCUC will play a key role in maintaining these linkages.

Project activities across the region will be carried out by funded activities prioritized by SAC. Coordination of, and participation in, these research activities will be carried out by NC CSC staff. Federal and university co-governance of these projects will be implemented to maintain strong coordinated efforts to provide a platform for engagement between the research community and the management entities in our region.

Over the first five years of funded projects at the NC CSC, each project as well as other partners will be apprised of the ReVAMP infrastructure and encouraged to have their results directed toward sustainable and operational tools that can contribute to, and demonstrate the utility of, ReVAMP. Also, the NC CSC will engage with the NCTC to make the ReVAMP known and available to students that participate in courses related to vulnerability assessment, structured decision making, and scenario planning. The NCTC is currently working with the NCCWSC and others to establish a DOI "climate curriculum" (Donna Brewer, NCTC, written commun., 26 Oct. 2012). NC CSC will work with the NCCWSC and the NCTC as this develops and build "ReVAMP" to ultimately serve as an operational resource available to students matriculating through that program and other resource managers interested in developing plans that incorporate the latest climate science into their management framework.

\section{References Cited}

Allen, C.D., Macalady, A.K., Chenchouni, H., Bachelet, D., McDowell, N., Vennetier, M., Kizberger, T., Rigling, A., Breshears, D.D., Hogg, E.H., Gonzalez, P., Fensham, R., Zhang, Z., Castro, J., Demidova, N., Lim, J.H., Allard, G., Running, S.W., Semerci, A., and Cobb, N., 2010, A global overview of drought and heat-induced tree mortality reveals emerging climate change risks for forests: Forest Ecology and Management, v. 259(4), p. 660-684.

\footnotetext{
${ }^{17}$ http://www.fort.usgs.gov/ram/
}

Brubaker, K.L., Dirmeyer, P.A., Sudradjat, Arief, Levy, B.S., Bernal, Fredric, 2001, A 36-yr climatological description of the evaporative sources of warm-season precipitation in the Mississippi River basin: J. Hydrometeor, v. 2, p. 537-557, doi: http://dx.doi.org/10.1175/15257541(2001)002<0537:AYCDOT>2.0.CO;2.

CCSP, 2008, The effects of climate change on agriculture, land resources, water resources, and biodiversity in the United States. A Report by the U.S. Climate Change Science Program and the Subcommittee on Global Change Research. P. Backlund, A. Janetos, D. Schimel, J. Hatfield, K. Boote, P. Fay, L. Hahn, C. Izaurralde, B.A. Kimball, T. Mader, J. Morgan, D. Ort, W. Polley, A. Thomson, D. Wolfe, M.G. Ryan, S.R. Archer, R. Birdsey, C. Dahm, L. Heath, J. Hicke, D. Hollinger, T. Huxman, G. Okin, R. Oren, J. Randerson, W. Schlesinger, D. Lettenmaier, D. Major, L. Poff, S. Running, L. Hansen, D. Inouye, B.P. Kelly, L. Meyerson, B. Peterson, R. Shaw: U.S. Department of Agriculture, Washington, D.C., U.S.A., 362 p.; available at http://www.climatescience.gov/ Library/sap/sap4-3/final-report/default.htm.

CCSP, 2009, Thresholds of Climate Change in Ecosystems, Fagre, D.B., C.W. Charles, C.D. Allen, Charles Birkeland, F.S. Chapin III, P.M. Groffman, G.R. Guntenspergen, A.K. Knapp, A.D. McGuire, P.J. Mulholland, D.P.C. Peters, D.D. Roby, and G. Sugihara: A Report by the U.S. Climate Change Science Program and the Subcommittee on Global Change Research: U.S. Geological Survey, Reston, VA.

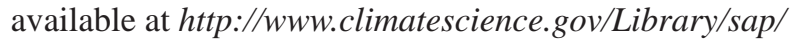
sap4-2/final-report/default.htm.

Cross, M.S., E. S. Zavaleta, D. Bachelet, M. L. Brooks, C. A. F. Enquist, E. Fleishman, L. J. Graumlich, C. R. Groves, L. Hannah, L. Hansen, G. Hayward, M. Koopman J. J. Lawler, J. Malcolm, J. Nordgren, B. Petersen, E. L. Rowland, D. Scott, S. L. Shafer, M. R. Shaw, G, M. Tabor, 2012, The adaptation for conservation targets (ACT) framework:A tool for incorporating climate change into natural resource management: Environmental Management, v. 50, p. 341-351, DOI 10.1007/s00267-012-9893-7.

Frid, L., and Wilmshurst, J.F., 2009, Decision analysis to evaluate control strategies for crested wheatgrass (Agropyron cristatum) in Grasslands National Park of Canada: Invasive Plant Science and Management, v. 2, p. 324-336.

Glick, P., Stein, B.A., and Edelson, N.A., eds., 2011, Scanning the conservation horizon: A guide to climate change vulnerability assessment: Washington, D.C., National Wildlife Federation, $176 \mathrm{p}$.

Intergovernmental Panel on Climate Change (IPCC), 2007, Climate change 2007: Synthesis report, in Core Writing Team, R.K. Pachuari, and A. Reisinger, eds., Contribution of working groups I, II, and III to the fourth assessment report of the Intergovernmental Panel on Climate Change: Genva, Switzerland, Intergovernmental Panel on Climate Change, 104 p. 
Jackson, S.T., Betancourt, J.L., Booth, R.K., and Gray, S.T., 2009, Ecology and the ratchet of events: Climate variability, niche dimensions, and species distributions: Proceedings of the National Academy of Sciences of the United States of America, v. 106, Supplement 2, p. 19685-19692, DOI: 10.1073/pnas.0901644106.

Karl, T. R., J. M. Melillo, and T. C. Peterson (eds), 2009, Global climate change impacts in the United States: Cambridge University Press, available on-line at http:// downloads.globalchange.gov/usimpacts/pdfs/climateimpacts-report.pdf. $188 \mathrm{p}$.

Kass, G.S., Shaw, R.S., Tew, T., and Macdonald, D.W., 2011, Securing the future of the natural environment: using scenarios to anticipate challenges to biodiversity, landscapes and public engagement with nature: Journal of Applied Ecology 2011, v. 48, p. 1518-1526.

Morisette et al., in press, VisTrails SAHM: visualization and workflow management for species habitat modeling: Ecography.

Milly, P.C.D., Betancourt, J., Falkenmark, M., Hirsch, R.M., Kundzewicz, Z.W., Lettenmaier, D.P., and Stouffer, R.J., 2008, Stationarity is dead: Whither water management?: Science, v. 319, no. 5863 p. 573-574.

National Academy, 2000, From research to operations in weather satellites and numerical weather prediction: Washington, D.C., National Academy Press, ISBN: 0-309-069416, 97 p., available at http://www.nap.edu/catalog/9948.html.

National Academy, 2002, The Missouri River ecosystem: Exploring the prospects for recovery: Washington, D.C., National Academy Press, ISBN: 0-309-08314-1, 189 p., available at http://www.nap.edu/catalog/10277.html.

Ojima, D., Steiner, J., McNeeley, S., Cozetto, K., and Childress, A., in press, Great Plains Regional Climate Assessment Technical Report, National Climate Assessment 2013: U.S. Global Change Research Program, Washington, DC, to be available on line at http://assessment.globalchange.gov.

Ray, A.J., Barsugli, J.J., Averyt, K.B., Wolter, K., Hoerling, M., Doesken, N., Udall, B., and Webb, R.S., 2008, Climate change in Colorado: A synthesis to support water resources management and adaptation: CU-NOAA Western Water Assessment, 58 p., available at http://wwa.colorado.edu/ CO_Climate_Report/index.html.

Salazar, Ken, 2009, Addressing the impacts of climate change on America's water, land, and other natural and cultural resources: Secretarial Order 3289, Sept. 14, 2009.

\section{Appendix 1: Contributors to the North Central Climate Science Center Five- Year Science Agenda}

Contributors to the initial science agenda developed under the direction of Dr. Jay Hestbeck, USGS, while he was serving as the interim NC CSC director in 2011.

- Dr. Caspar Amman, NCAR, Research Scientist

- Leslie Armstrong, USGS, South Central Regional Executive Office

- Dr. Kristen Averyt, University of Colorado, Deputy Director, Western Water Assessment

- James Broska, FWS, GP LCC Science Coordinator

- Dr. Lawrence Buja, NCAR, Director of Climate Applications

- Pamela Fromhertz, NOAA

- Dr. Jay Hestbeck, USGS, Interim Center Director, NC CSC

- Dr. Doug Kluck, NOAA

- Dr. Richard Nelson, FWS, PPP LCC Coordinator

- Dr. Dennis Ojima, Colorado State University, Host University PI

- Dr. Max Post van der Burg, USGS, PPP LCC

- Dr. Andrea Ray, NOAA, Earth Systems Research Laboratory

- Dr. Richard Sojda, USGS, GN LCC

- Dr. Robert (Robin) Webb, NOAA, Earth Systems Research Laboratory

- Dr. Cathy Whitlock, Montana State University

Participants in the strategic planning meeting that was integral in the development of the five-year science agenda are as follows: 


\begin{tabular}{|c|c|c|c|c|}
\hline First Name & Last Name & Institution/Organization & Phone Number & Email \\
\hline Christopher & Anderson & Iowa State University & $515-294-9948$ & cjames@iastate.edu \\
\hline Mark & Anderson & USGS - South Dakota & $605-394-3220$ & manders@usgs.gov \\
\hline Nikki & Blanken & Colorado State University & $970-491-5589$ & nikki.blanken@colostate.edu \\
\hline Kyle & Blasch & Montana Water Science Center & $406-457-5901$ & kblasch@usgs.gov \\
\hline Zachary & Bowen & USGS Fort Collins Science Center & $970-226-9218$ & bowenz@usgs.gov \\
\hline James & Broska & Great Plains LCC & $505-248-6279$ & James_Broska@fws.gov \\
\hline Craig & Carr & Montana State University & 406-994-3282 & craig.carr@montana.edu \\
\hline Frank & D'Erchia & USGS Rocky Mountain Area & $303-236-1460$ & fderchia@usgs.gov \\
\hline Gary & Davis & Bureau of Reclamation & $406-247-7717$ & jgdavis@usbr.gov \\
\hline Diane & Debinski & Iowa State University & $515-294-2460$ & Debinski@iastate.edu \\
\hline Deborah & Finch & USDA Forest Service & $505-724-3671$ & dfinch@fs.fed.us \\
\hline Robert & Gleason & USGS Northern Prairie Wildlife Research Center & $701-253-5546$ & rgleason@usgs.gov \\
\hline Bob & Gough & Intertribal Council on Utility Policy & 6054418316 & gough.bob@gmail.com \\
\hline Andrew & Hansen & Montana State University & 4069946046 & hansen@montana.edu \\
\hline Todd & Hawbaker & USGS Rocky Mountain Geographic Science Center & $303-202-4303$ & tjhawbaker@usgs.gov \\
\hline Lauren & Hay & USGS & 3032367279 & lhay@usgs.gov \\
\hline Steven & Hostetler & USGS & $541737-8928$ & swhostet@usgs.gov \\
\hline Kevin & Johnson & Southern Rockies LCC & $303-236-4404$ & kevin_m_johnson@fws.gov \\
\hline Jeff & Kershner & USGS NOROCK & 406-994-5304 & jkershner@usgs.gov \\
\hline Todd & Kipfer & Montana Institute on Ecosystems & 406-994-7977 & tkipfer@montana.edu \\
\hline Kate & Kitchell & Bureau of Land Management & $406-896-5012$ & kkitchell@blm.gov \\
\hline Doug & Kluck & NOAA/Regional Climate Services Director & $816-564-2417$ & doug.kluck@noaa.gov \\
\hline William & Lauenroth & University of Wyoming & $307-766-4353$ & wlauenro@uwyo.edu \\
\hline Jeff & Morisette & DOI North Central Climate Science Center & $970-691-8197$ & morisettej@usgs.gov \\
\hline Rick & Nelson & U.S. Fish and Wildlife Service & $701-355-8509$ & Richard_D_Nelson@fws.gov \\
\hline Barry & Noon & Colorado State University & $970-491-7905$ & brnoon@cnr.colostate.edu \\
\hline Robin & O'Malley & USGS NCCWSC & $703-648-4086$ & romalley@usgs.gov \\
\hline Robert & Oglesby & University of Nebraska, Lincoln & $402-472-1507$ & roglesby2@unl.edu \\
\hline Dennis & Ojima & Colorado State University & $970-491-1976$ & dennis.ojima@colostate.edu \\
\hline Tom & Olliff & Great Northern LCC & 406-994-7920 & Tom_Olliff@nps.gov \\
\hline Casey & Peters & UC Davis & $707-292-8485$ & caseybpeters@yahoo.com \\
\hline Max & Post van der Burg & USGS Northern Prairie Wildlife Research Center & $701-253-5574$ & maxpostvanderburg@usgs.gov \\
\hline Andrea & Ray & NOAA/EArth System Research Lab & $303-497-6434$ & Andrea.ray@noaa.gov \\
\hline Steve & Running & University of Montana & $406-243-6311$ & swr@ntsg.umt.edu \\
\hline Liz & Shanahan & Montana State University & $406-994-5167$ & shanahan@montana.edu \\
\hline Rick & Sojda & USGS; Great Northern LCC & $406-994-1820$ & sojda@usgs.gov \\
\hline Cathy & Thomas & USGS & $970-226-9164$ & ccullinanethomas@usgs.gov \\
\hline Jim & Vogelmann & USGS/EROS & $605-594-6062$ & vogel@usgs.gov \\
\hline Cathy & Whitlock & Montana Institute on Ecosystems & $406-994-6910$ & whitlock@montana.edu \\
\hline Mark & Wildhaber & USGS Columbia Environmental Research Center & $573-876-1847$ & mwildhaber@usgs.gov \\
\hline
\end{tabular}




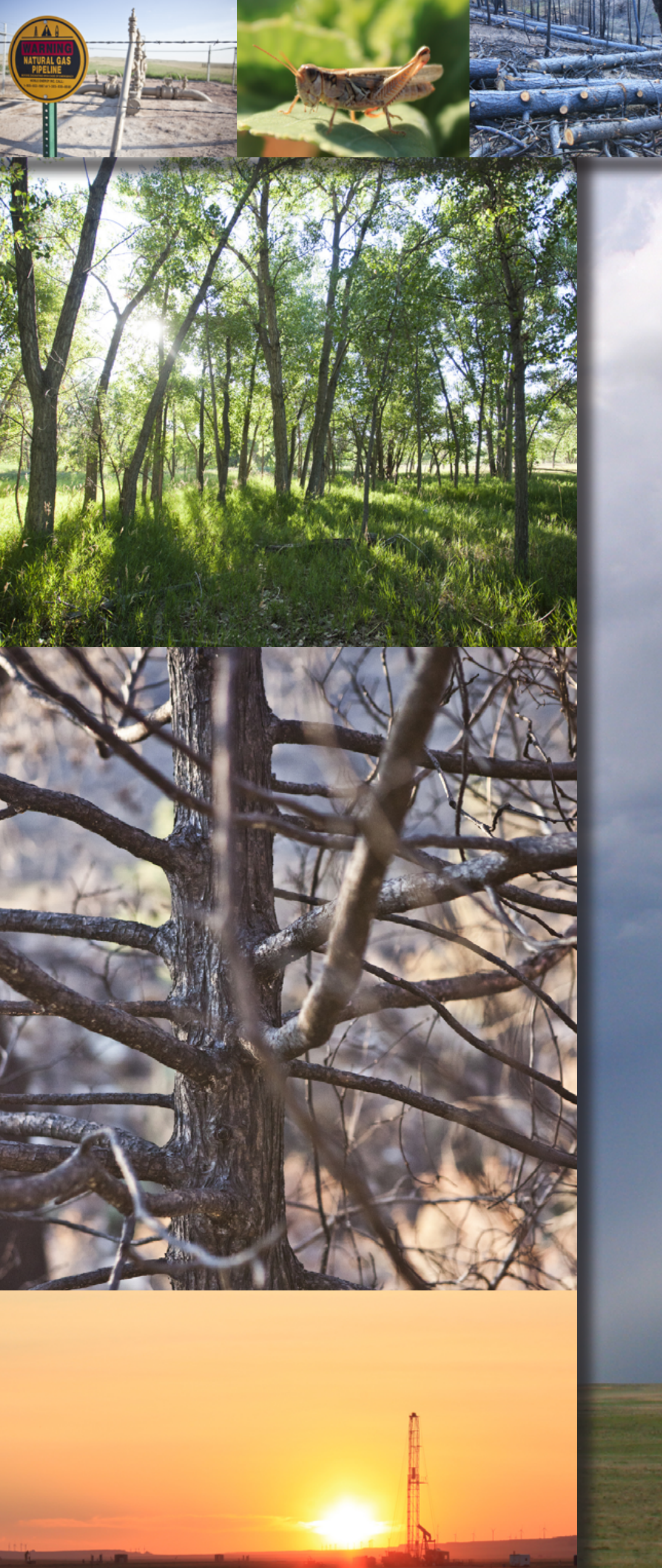

